\title{
My Last Brush Stroke
}

\author{
Myrella Roy, Executive Director, 2003-2018
}

$\mathrm{T}$ he year 2018 marked the end of my tenure as chief staff officer of the Canadian Society of Hospital Pharmacists (CSHP), after more than 15 amazing and rewarding years. By the time you read these lines, I will have embarked on the retirement chapter of my life. In the present report, I would like to take you through the extensive gallery of CSHP's accomplishments exhibited during this last year and over the past 15 years.

The Steering Committee of the Excellence in Hospital Pharmacy masterpiece program drew inspiration from the responses to surveys of patients and CSHP members conducted in late 2017. These surveys requested valuation of how the 3 program themes-patient-centred care, best practice, and communication and collaboration-are expressed in the care provided to patients by hospital pharmacy teams. Based on the survey responses, realistic and aspirational targets were set to measure the performance of care embodied in the priority themes. The survey report (entitled What Patients and Members Told Us about Patient Care), the program's targets, and issues of the new electronic newsletter, Excellence Express, are available at https://www.cshp.ca/excellence.

Thanks to input from the organization's muses, its members, CSHP engaged in the Choosing Wisely Canada movement (https://choosingwiselycanada.org/recommendations/). Six recommendations were drawn, appealing for pharmacists practising in hospitals and other collaborative healthcare settings to reduce commonly used but unnecessary drug treatments that are not supported by evidence and could expose patients to harm.

CSHP and the Association des pharmaciens des établissements de santé du Québec (A.P.E.S.) produced a collective artwork: an entirely revised strategic alliance that depicts an exciting new opportunity for the members of both organizations. Current CSHP members can now avail themselves of the same benefits and services as those enjoyed by A.P.E.S. associate members, at no additional cost. Similarly, CSHP offers to interested A.P.E.S. active members the same rights and benefits as it grants to its individual supporters, at no additional cost. Through their renewed strategic alliance, CSHP and A.P.E.S. are also endeavouring to accentuate their advocacy voice throughout
Canada-promoting how pharmacists from hospitals and other collaborative healthcare settings contribute to the improvement of the health and quality of life of Canadians - and to foster nationwide exchanges and consultation among hospital pharmacy experts. In the advocacy ex-

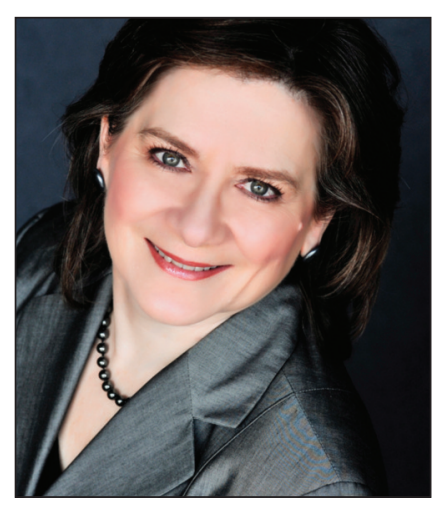
hibition room, 2 illustrative topics were prominently displayed on easels. First, CSHP responded to an invitation from the Advisory Council on the Implementation of National Pharmacare to recommend Society members who could speak authoritatively about pharmacare and represent the organization's position in a series of cross-Canada roundtables during the summer. Of the 33 members recommended by CSHP, 14 were invited by the Advisory Council to 9 roundtables. The Advisory Council's final report is expected in the spring of 2019. Second, CSHP has continued to voice to Health Canada the concerns of its membership about the mandatory reporting by hospitals of serious adverse drug reactions and medical device incidents. This advocacy effort entailed making representations on the proposed amendments to Canada's Food and Drug Regulations and the accompanying cost-benefit analysis; twice participating with A.P.E.S., at Health Canada's invitation, in private discussions on the proposed regulations and on next steps toward their enactment; and joining the Advisory Panel on Outreach, Education and Feedback.

Also showcased in the gallery were CSHP's responses to calls for consultation from the following stakeholders: Health Canada, on proposed regulations on the monitoring of medical assistance in dying, on the renewal of the Special Access Programme, and on the notice of intent to restrict the marketing and advertising of opioids and the subsequent cost-benefit analysis of the related proposal; and HSO (Health Standards Organization), on the Medication Management standard. 
CSHP added several valuable items to its collection: the Canadian Medication Optimization Briefing Safe Transitions of Care for Patients Taking Opioids (https://www.cshp.ca/canadianmedication-optimization-briefing-0), the Hospital Pharmacy in Canada Report 2016/17 (www.hospitalpharmacysurvey.ca), and the Telepharmacy: Guidelines (https://www.cshp.ca/guidelines). CSHP's artists in residence are also putting the finishing touches on a monumental work, Controlled Drugs and Substances in Hospitals and Healthcare Facilities: Guidelines on Secure Management and Diversion Prevention, which will be on open display very soon. Furthermore, CSHP and other healthcare organizations partnered in the Royal College of Physicians and Surgeons of Canada's project to create the ebook Navigating Medical Emergencies: An Interactive Guide to Patient Management (https://www.cshp.ca/clinical-pharmacy); Hospital News collaborated with CSHP to portray hospital pharmacy practice in its June 2018 edition (https://issuu.com/hospitalnews/docs/ hospital_news_june_2018_edition); and Elsevier-a global information analytics business specializing in science and health-commissioned CSHP to paint the chapter "Hospital Pharmacy Practice: A Case Study from Canada" in the original edition of Encyclopedia of Pharmacy Practice and Clinical Pharmacy, which is expected to be released online in June 2019 (https://www.elsevier.com/books/ encyclopedia-of-pharmacypractice-and-clinical-pharmacy/ babar/978-0-12-812735-3).

Art galleries and CSHP alike are embracing technology with similar ends in mind: the former to engage visitors and enrich their experience with art, the latter to better engage its members and enrich their experience with the organization. In the past year, CSHP has upgraded its association management system, the computer software that supports the provision of services to members. Through the system's interface with the enhanced member portal on CSHP's website, members can more easily manage their profile online, interact and transact with the organization, and contact their peers.

CSHP has continued to flourish under the watchful eye of its staff curators. Each and every one of these 15 dedicated employees deserves public accolade, with a few highlighted here for appreciation in 2018. Several milestone employment anniversaries were celebrated: 5 years for Susan Maslin (Event Planning and PSNs Administrator), 10 years for Cathy Lyder (Director, Members and Programs), 15 years for Janet Lett (CSHP Foundation Administrator), and 25 years for Gloria Day (Canadian Pharmacy Residency Board Administrator). Laurie Frid (General Program Administrator) and Amanda Iannaccio (Publications Administrator) were welcomed back, Laurie after her leave of absence and Amanda after her pregnancy and parental leave. Finally, Christopher Doody (Interim Publications Administrator) and Olga Chrzanowska (Web Administrator for nearly 10 years) received warm send-offs.

As for the 15-year retrospective, contrary to the idiom "a picture is worth a thousand words", I leave you with hundreds of words sketching an Impressionist picture: a word cloud generated from all of my Executive Director's Reports.

With my undying gratitude,

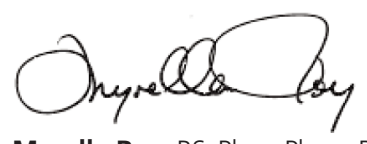

Myrella Roy, BScPhm, PharmD, FCCP Former Executive Director (2003-2018) Canadian Society of Hospital Pharmacists

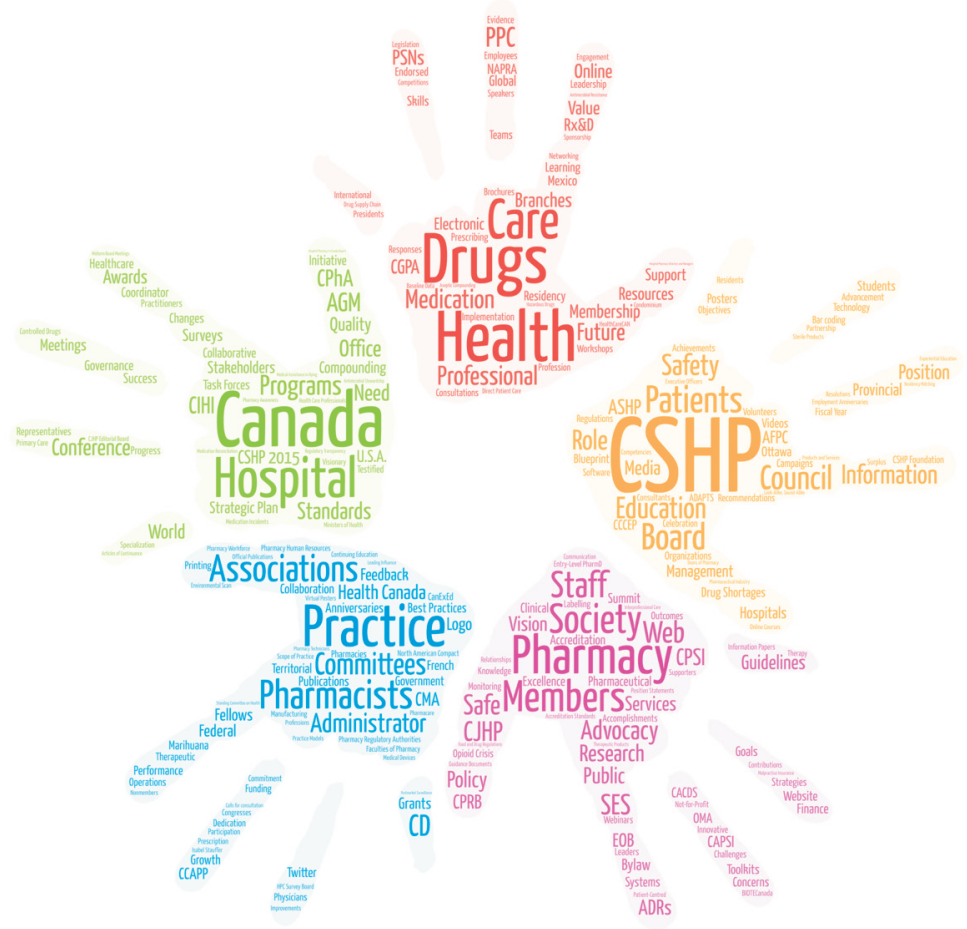

